\title{
Predictors of Weight Loss Maintenance following an Insurance-Sponsored Weight Management Program
}

\author{
Christiaan G. Abildso, ${ }^{1}$ Olivier Schmid, ${ }^{2}$ Megan Byrd, ${ }^{3}$ Sam Zizzi, ${ }^{3}$ \\ Alessandro Quartiroli, ${ }^{4}$ and Sean J. Fitzpatrick ${ }^{5}$ \\ ${ }^{1}$ Department of Social and Behavioral Sciences, West Virginia University School of Public Health, P.O. Box 9190, \\ Morgantown, WV, 26506-9190, USA \\ ${ }^{2}$ Institute of Sport Science, University of Bern, 3012 Bern, Switzerland \\ ${ }^{3}$ College of Physical Activity and Sport Sciences, West Virginia University, Morgantown, WV 26506-6116, USA \\ ${ }^{4}$ Department of Psychology, University of Wisconsin-La Crosse, La Crosse, WI 54601, USA \\ ${ }^{5}$ College of Graduate and Professional Studies, John F. Kennedy University, Pleasant Hill, CA 94523-4817, USA
}

Correspondence should be addressed to Christiaan G. Abildso; cgabildso@hsc.wvu.edu

Received 21 October 2013; Revised 6 January 2014; Accepted 27 January 2014; Published 11 March 2014

Academic Editor: Aron Weller

Copyright ( 2014 Christiaan G. Abildso et al. This is an open access article distributed under the Creative Commons Attribution License, which permits unrestricted use, distribution, and reproduction in any medium, provided the original work is properly cited.

\begin{abstract}
Intentional weight loss among overweight and obese adults (body mass index $\geq 25 \mathrm{~kg} / \mathrm{m}^{2}$ ) is associated with numerous health benefits, but weight loss maintenance (WLM) following participation in weight management programming has proven to be elusive. Many individuals attempting to lose weight join formal programs, especially women, but these programs vary widely in focus, as do postprogram weight regain results. We surveyed 2,106 former participants in a community-based, insurance-sponsored weight management program in the United States to identify the pre, during, and post-intervention behavioral and psychosocial factors that lead to successful WLM. Of 835 survey respondents (39.6\% response rate), 450 met criteria for inclusion in this study. Logistic regression analyses suggest that interventionists should assess and discuss weight loss and behavior change perceptions early in a program. However, in developing maintenance plans later in a program, attention should shift to behaviors, such as weekly weighing, limiting snacking in the evening, limiting portion sizes, and being physically active every day.
\end{abstract}

\section{Introduction}

Intentional weight loss among overweight and obese adults (body mass index $\geq 25 \mathrm{~kg} / \mathrm{m}^{2}$ ) is associated with numerous health benefits. Reviews of the literature suggest that diet-plus-physical activity weight loss interventions produce greater weight losses than diet-only interventions $[1,2]$. However, weight loss maintenance (WLM) continues to be the Achilles heel of many such interventions, with postprogram weight regains in diet-plus-physical activity lifestyle interventions of generally $50 \%$ by one year after intervention $[1,3]$. A systematic review of studies published between 1966 and 2008 suggests that 2 to $54 \%$ of lifestyle intervention participants achieve intentional WLM $[3,4]$. This wide variation in rate of "successful losers" is primarily accounted for by inconsistent definitions of WLM, which is commonly conceptualized as a combination of achieving a specified minimum weight loss and sustaining it over a certain period of time $[3,4]$.

Various criteria have been used in the literature to determine successful WLM, including the duration of the active weight loss and weight maintenance phases, the amount of weight loss during the active and maintenance phases, the types of interventions, and the times of assessment. Maintaining a $5-10 \%$ weight loss has been shown to have clinically significant health benefits $[5,6]$ and an increase by $50 \%$, the likelihood of successful maintenance over five years [7]. An even lower amount of initial weight loss may have additional benefits for WLM, as higher amounts of weight loss do not improve the prediction of WLM [3] and may be associated with weight regain, cycling, yo-yo dieting, and ill health 
[8-10]. Stevens and colleagues [11] further recommended that a weight change of $\pm 3 \%$ is to be considered weight maintenance, weight changes ranging from $3 \%$ to $5 \%$ is to be considered small weight fluctuations, and weight loss of $>5 \%$ is to be considered clinically significant. Despite the lack of definitional consensus, adopting more inclusive definitions of weight loss maintenance that allows for some regain following loss appears to provide participants with the most health benefits $[4,7]$.

Methodological concerns notwithstanding, a variety of behavioral and psychosocial predictors have been identified to account for successful WLM. Individuals who have successfully achieved self-directed WLM have been found to be more physically active during their period of weight loss than their unsuccessful peers $[12,13]$. In addition, eating behaviors such as consuming breakfast regularly, reducing portion size, and limiting snacking have been found to predict lower caloric intake [14-17]. Self-monitoring strategies, such as keeping a food and exercise log and frequent weighing, have also been found to be critical for WLM [7, 13, 14, 18, 19]. Psychosocial predictors have commonly included receiving social support from a weight maintenance group or friends, but the beneficial impact of spousal participation has remained inconsistent [4]. In addition to the findings about social support, autonomy and self-reliance have also predicted successful WLM [20].

National Weight Control Registry research suggests that the majority of successful weight loss maintainers, especially women, participate in a formal program to achieve initial weight loss [13] and keep using the behavior change strategies learned during the interventions after the intervention is completed [7]. Large corporations and health insurance companies worldwide have a key role to play in incentivizing participation in weight management programming and have started investing in such initiatives $[21,22]$. Therefore, defining the most effective in-program strategies to prevent weight regain following weight loss is critical for weight management interventions [3]. The purpose of this study was to identify the pre-, during, and postintervention behavioral and psychosocial factors that lead to successful WLM following participation in an insurance-sponsored diet-plus-physical activity community-based intervention.

\section{Methods}

2.1. Participants. West Virginia Public Employees Insurance Agency (PEIA) members that enrolled in PEIA's weight management program (WMP) benefit between April 1, 2005, and June 30, 2008, were recruited to complete a program evaluation and postprogram health behavior survey in February $2009(N=2,106)$. The enrollment dates were chosen to ensure that all participants contacted had the time to have completed at least six months of the WMP by the time study recruitment began. A full evaluation and details of the WMP $[23,24]$ are available. Briefly, the WMP is an insurance benefit that provides access to exercise and nutrition professionals for a small monthly copayment at private exercise facilities with intervention services decreasing as participants progress through the program of up to two years (see Table 1 for details). Facilities are reimbursed by PEIA for services provided using a predetermined fee schedule, and participant progress is tracked by care management nurses. A 12-pound weight loss is expected of participants by the end of month 3 of the WMP. Otherwise, no weight loss, calorie intake, or physical activity goal is mandated or strictly enforced. Participants may also be removed from the program for noncompliance with the following behavioral expectations: exercising at their site at least twice per week; turning in food logs periodically; attending appointments with the exercise physiologist, registered dietitian, and personal trainer; and having monthly body measurements taken by site staff. Professional exercise and nutrition services are provided following relevant guidelines for weight loss and maintenance (e.g., American College of Sports Medicine, American Dietetic Association).

This study was approved by the West Virginia University Institutional Review Board. Using a modified version of Dillman's [25] recruiting method; eligible participants $(N=$ $2,106)$ were contacted by mail and/or email up to five times over the course of six weeks to complete a program evaluation and postprogram health behavior survey (see Figure 1). All 2,106 eligible participants were sent a letter in February 2009 notifying them that a survey would be forthcoming and were sent a follow-up by email $(n=1,056)$ or mail $(n=1,050)$ with a link to, or a hard copy of, the survey depending on the availability of a valid email address. Those with a valid email address were sent two reminders before being mailed a hard copy of the survey. Surveys were mailed to those with invalid email addresses $(n=332)$. These participants, and those without an email address, were sent a follow-up letter within three weeks of receiving the hard copy of the survey if they had not filled out and returned the survey. To encourage participation, the opportunity to enter a random drawing for 100 recipients to receive a free health-related book was offered.

2.2. Instrumentation. Participants were asked to complete a program evaluation survey containing a mix of open-ended and closed-ended items in sections categorized chronologically as they related to the WMP (i.e., pre-, during, and postprogram). Each section had a prompt to ensure the respondent was evaluating the correct time period (e.g., "The next set of questions asks you about your participation in the Program"). The survey sections and items pertinent to this study of WLM are described in detail below.

2.2.1. Preprogram Factors. The first section of the survey contained items assessing preprogram factors including demographic information, physical activity and weight loss history, and bariatric surgery intention.

Demographic Information. Survey items assessed demographic information including age, gender, marital status, and number of dependents in the home (i.e., caregiver status). Based on response distribution, age was categorized as $<45$ years, 45-54.9 years, or $\geq 55$ years; marital status was categorized as married or unmarried (single/divorced/widowed). 
TABLE 1: Minutes of services per participant and monthly reimbursement made by the insurer during the weight management program.

\begin{tabular}{lccccccccccccccc}
\hline \multirow{2}{*}{ Service } & \multicolumn{3}{c}{ Phase I (months 1-3) } & \multicolumn{4}{c}{ Phase II (months 4-12) } & \multicolumn{4}{c}{ Phase III (months 13-24) } \\
& M1 & M2 & M3 & M4 & M5 & M6 & M7 & M8 & M9 & M10 & M11 & M12 & M13 & M14-24 \\
\hline Registered dietitian & 60 & - & 60 & - & - & 30 & - & - & 30 & - & - & - & 60 & - \\
Fitness assessment & 60 & - & 60 & - & - & 30 & - & - & 30 & - & - & - & 60 & - \\
Personal training & 30 & 30 & 30 & 15 & 15 & 15 & 15 & 15 & 15 & 15 & 15 & 15 & 15 & $15 / m_{0}$ \\
Member copayment & $\$ 45$ & $\$ 45$ & $\$ 45$ & $\$ 14$ & $\$ 14$ & $\$ 14$ & $\$ 14$ & $\$ 14$ & $\$ 14$ & $\$ 14$ & $\$ 14$ & $\$ 14$ & $\$ 25 \max ^{\mathrm{a}}$ & $\$ 25 \max ^{\mathrm{a}}$ \\
Agency payment to facility & $\$ 246.67$ & $\$ 246.67$ & $\$ 246.67$ & $\$ 32$ & $\$ 32$ & $\$ 32$ & $\$ 32$ & $\$ 32$ & $\$ 32$ & $\$ 32$ & $\$ 32$ & $\$ 32$ & $\$ 25 \max ^{\mathrm{a}}$ & $\$ 25 \max ^{\mathrm{a}}$
\end{tabular}

a: member copayment (and insurance agency payment to the facility) during months 13-24 is one-half of the facility's maximum published private membership fee up to a maximum of $\$ 50$.
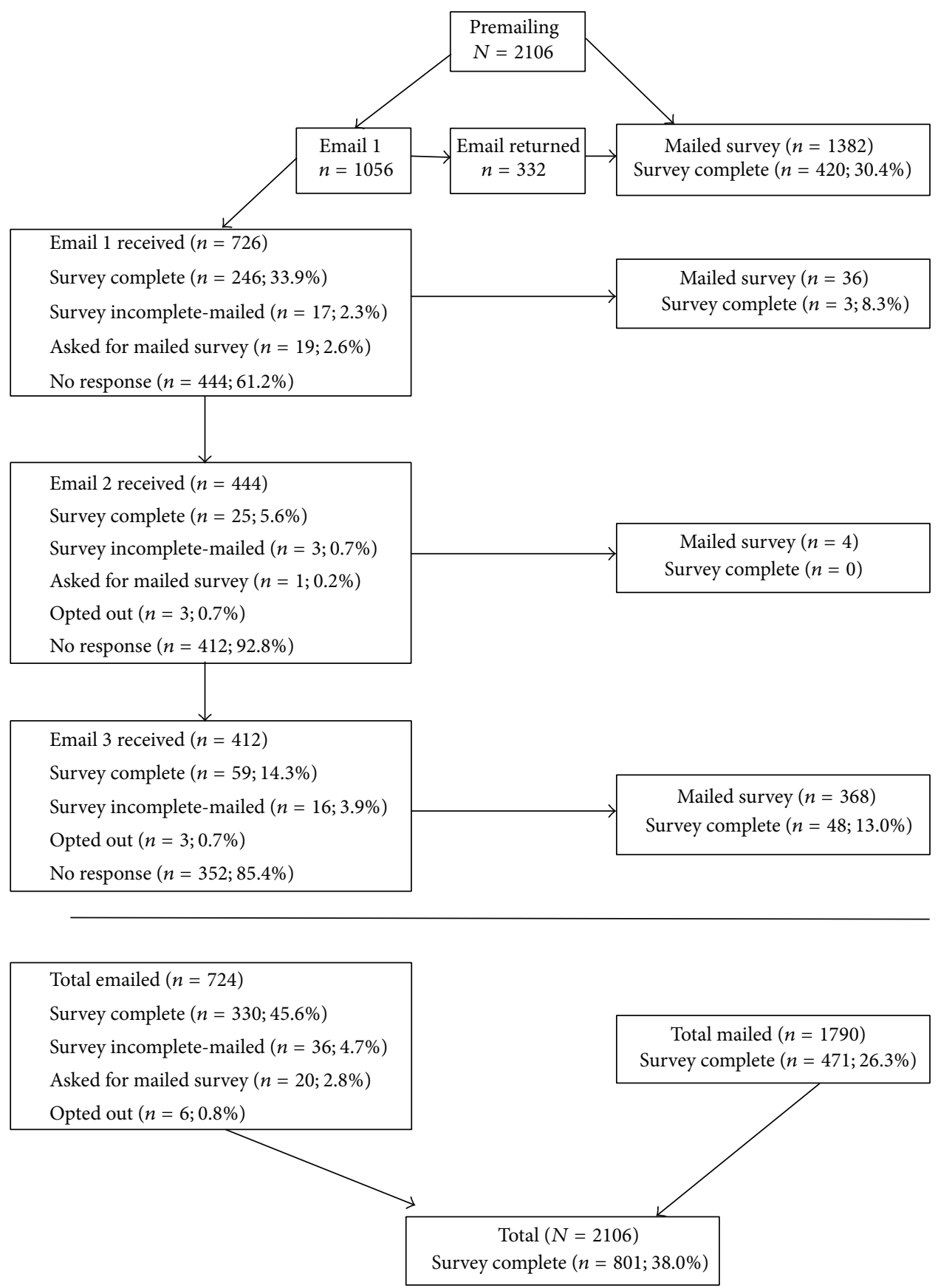

FIGURE 1: Sample phases and response rates. 
Caregiver status was determined by using the number of dependents in the home item to categorize the respondent as a caregiver (one or more dependents in the home) or noncaregiver (zero dependents in the home). Race and employment statuses were not used as predictors because over $90 \%$ of participants are white (reflective of the population of West Virginia) and full-time employees eligible for this insurance benefit.

Physical Activity and Weight Loss History. Physical activity was determined using condensed versions of Behavioral Risk Factor Surveillance System (BRFSS) physical activity module items [26]. Separate items queried participants to retrospectively assess the number of days in a usual week that they did 30 or more minutes of moderate physical activity (MPA) and 20 or more minutes of vigorous physical activity (VPA) in the six months prior to entering the WMP. Because of the retrospective nature of this item, responses were categorized into sedentary (zero MPA and VPA) versus any activity (nonzero MPA or VPA). The number of weight loss attempts was used to assess weight loss history. Responses were categorized into quartiles for analysis $(<5,5-9,10-19$, or $\geq 20$ ). Participants were also asked if they were considering bariatric surgery before joining the WMP (yes/no).

2.2.2. In-Program Factors. In the second section of the survey, respondents were asked to evaluate in-program factors including perceptions of weight loss, effort, and success and difficulty of health behavior change and maintenance as they progressed through Phase I of the program (months 1-3) and beyond.

Perception of Weight Loss, Effort, and Success. To understand perception of initial weight loss, participants were asked to rate their weight loss during Phase I as Excellent, Good, Acceptable, Poor, or Disappointing. This was condensed based on response distribution as Excellent/Good, Acceptable, or Poor/Disappointing. In addition, they were asked to provide numerical ratings for their perceived effort during Phase I from 0 (least) to 100 (most) and success during Phase 1 from 0 (worst) to 100 (most). Based on prior research [27], these responses were compared and condensed into three categories for analysis (success $>$ effort, success $=$ effort, or success $<$ effort).

Perceived Difficulty of Health Behavior Change and Maintenance. Perceived difficulty of initial health behavior change was assessed using multiple items to rate the difficulty of losing weight, changing diet routine, and starting an exercise routine during Phase I on a six-point scale from 1 (extremely easy) to 6 (extremely difficult). Perceived difficulty of maintaining these health behavior changes was assessed similarly, using items to rate the difficulty of sticking with diet changes and continuing an exercise routine beyond Phase I on a six-point scale from 1 (extremely easy) to 6 (extremely difficult). Responses were split at the midpoint to dichotomize the variables to easy (responses 1-3) versus difficult (responses 4-6).
2.2.3. Postprogram Factors. In the final section of the survey, we assessed postprogram factors (i.e., current health behaviors). These included current physical activity level, weight management behaviors, food management strategies, and current height and weight.

Current Physical Activity. Physical activity was assessed using condensed versions of items from the physical activity module of the BRFSS [26]. Separate items asked the respondent to assess the number of days in a usual week; they did 30 or more minutes of MPA and 20 or more minutes of VPA. Responses were categorized into sedentary (zero MPA and VPA), insufficiently active (not meeting MPA or VPA guidelines), or sufficiently active (meeting MPA and/or VPA guidelines).

Weight Management Behaviors. Behaviors associated with WLM were assessed in the instrument, including frequency of self-weighing (never, <1 time per week, weekly but not daily, and daily), current method of weight loss (not currently trying to lose weight, activity or diet alone, and activity and diet in combination), frequency of eating breakfast (daily, not daily), logging physical activity (yes, no), and currently exercising at a gym, or WMP facility (yes, no).

Food Management Behaviors. Seven behavioral food strategies to maintain weight associated with WLM were also assessed in the instrument by asking the respondent to endorse which strategies they were currently using. These strategies included counting calories, limiting the amount of fat consumed, eating out less often, limiting portion size at meals, keeping a food log or journal, limiting soda and sweetened drinks, and limiting snacking in the evening. All were coded as yes/no based on respondent endorsement or not.

2.3. Weight Data, Length of Time in Program, and Length of Time after Program. Fitness and exercise professionals at facilities measure participant data monthly, including height, weight, and body mass index (BMI). Each site determines its measurement protocols on the basis of available instruments and staff training. While protocols and instrumentation may vary across facilities, they do not vary within facilities over time. Data are entered into a secure database from which data were extracted for the current study. Baseline and final program measurements were used to calculate baseline BMI $\left(25-29.9,30-34.9,35-39.9\right.$, and $\left.\geq 40 \mathrm{~kg} / \mathrm{m}^{2}\right)$ and percentage of baseline weight lost during the program. In-program weight loss was categorized as clinically significant $(\geq 5 \%)$ or nonclinically significant ( $<5 \%$ ) [28-30]. Further, because each data point has a date associated with it, these data were used to calculate the length of time each participant remained in the program. Six months is generally the point at which habits are formed [31], the common length of weight management interventions, and the point at which weight loss peaks in these interventions [32-34]. Further, the WMP moves to a minimal "maintenance" intervention period (Phase III) after the 12th month. Thus, length of time in the program was classified as $\leq 6$ months, $>6-12$ months, or 
$>12$ months. Lastly, the final measurement date and the date of the survey response were used to calculate the postprogram time, classified as $\leq 6$ months, $>6-12$ months, $>12-24$ months, or $>24$ months.

2.4. Analyses. Statistical analyses were conducted using SPSS version 19.0. Comparisons of successful maintainers (SM) and unsuccessful maintainers (UM) of weight loss were conducted using independent samples $t$-tests for continuous dependent variables or chi-square analyses for categorical dependent variables. Forward stepwise logistic regression analysis, an effective exploratory technique $[35,36]$, was conducted to identify the predictors of WLM, our outcome of interest. We operationalized WLM as any participant that met the following criteria: (a) lost any amount of weight during the WMP, (b) maintained that weight loss or regained $<4 \%$ of postprogram weight during the time from program end to survey completion, and (c) achieved overall weight loss during the preprogram to survey completion time point. As called for in recent literature, this is a very inclusive operationalization of WLM which allows for moderate shortterm losses that may lead to greater losses over the longer term, excludes extreme weight loss changes, and allows for minimal regain postintervention $[4,11]$.

Four regression models were run to determine factors to include in a final predictive model. Repeated contrasts were used for each predictor variable in each model. This method compares each category of a predictor (except the first) to the previous category. Thus, contrasts include categories 1 versus 2,2 versus 3 , and 3 versus 4 , rather than the simple contrasts of categories 1 versus 2, 1 versus 3, 1 versus 4 , and so on. This allows for pinpointing specific frequencies of behaviors, such as self-weighing and amount of PA, predictive of WLM.

Model A (preprogram) included four demographic factors (age, gender, marital status, and caregiver status), physical activity level, whether weight loss surgery was being considered or not, and objectively measured baseline BMI. Model B (in-program) consisted of nine factors, including perception of weight loss, difference between perceived effort and success, five perceived difficulties of health behavior change items, and objectively measured percentage weight loss and length of time in the program. Model C (postprogram 1) included seven factors, specifically length of time from program end to survey completion date, frequency of self-weighing, current method of weight loss, frequency of eating breakfast, logging physical activity, and currently exercising at a gym or WMP facility. Model D (postprogram 2) consisted of seven food management behavioral factors including counting calories, limiting the amount of fat consumed, eating out less often, limiting portion size at meals, keeping a food log or journal, limiting soda and sweetened drinks, and limiting snacking in the evening.

Predictors significant at the $P<0.05$ level from Models A-D were included in the final model. Odds ratios (ORs) and 95\% confidence intervals (CI) are reported for successfully achieving WLM as operationalized in this study. Because we used repeated contrasts for each predictor variable, ORs should be interpreted as the change in the likelihood of being a successful maintainer (SM) that results in a one-unit increase in the predictor variable. Thus an $\mathrm{OR}>1$ should be interpreted as an increase, and $\mathrm{OR}<1$ should be interpreted as a decrease, in the likelihood of being a SM with a one-unit increase in the predictor.

\section{Results}

3.1. Response and Baseline Data. A total of 835 surveys were received (39.6\% response rate), 801 of which were complete. From these, 351 completed surveys were removed because they did not have a weight measurement following baseline $(n=26)$, had a baseline BMI $<25 \mathrm{~kg} / \mathrm{m}^{2}(n=3)$, became pregnant during the program $(n=4)$, had bariatric surgery postprogram $(n=7)$, did not report a current weight $(n=$ $21)$, were still active in the program when they completed the survey $(n=154)$, were $<1$ month after program at the time of survey completion $(n=39)$, were duplicate entries from the same individual across survey platforms $(n=2)$, or had gained weight during the program $(n=95)$. The resulting analytic sample size was $N=450$. Our sample was largely females (81.1\%), married ( $74.9 \%)$, and 45 years or older (74.2\%).

Nearly half of the respondents were successful at WLM $(n=210,46.7 \%)$. Independent samples $t$-tests showed that SM and UM did not achieve significantly different percentage weight loss during the program ( $6.4 \%$ versus $7.2 \% ; P=0.157$ ) but did achieve significantly different weight change after program and overall from preprogram to current time $(P<$ 0.001 ). In fact, SM lost $2.4 \%$ of end program weight and lost $8.6 \%$ of preprogram weight overall, a clinically significant loss [37]. In comparison, UM gained $9.6 \%$ postprogram and gained $1.5 \%$ from preprogram. A greater percentage of SM were meeting PA guidelines after program than UM (43.8\% versus $24.7 \%$ ), and fewer SM than UM were insufficiently active ( $41.3 \%$ versus $51.5 \%)$ or sedentary ( $14.9 \%$ versus $23.8 \%)$ after program $\left(\chi^{2}=19.000 ; P<0.001\right)$.

3.2. Predictors of WLM. Items included in, and results of, Models A-D are presented in Tables 2, 3, 4, and 5. Please note that the size of the analytic sample in each model varies because SPSS performs a listwise deletion of missing data when running logistic regression. Thus, if there is a missing value for any variable in the model, the entire case is excluded from the analysis. Tables $2-5$ present all potential predictor variables in the order in which the repeated contrasts were conducted. The Wald chi-square statistic, which indicates whether $\beta$ for each variable is significantly different than zero and the variable is a significant predictor of weight loss maintenance [35], is reported for all variables, but an OR is only reported for significant predictors. Larger values of the Wald statistic indicate a variable more likely to be a significant predictor of the outcome.

Preprogram physical activity level was the only significant predictor of WLM from regression Model A, with SM more likely to have been getting any physical activity before WMP than UM (OR $=1.62,95 \%$ CI $=1.05-2.51)$. Regression Model $\mathrm{B}$ revealed that respondents completing $>6-12$ months of the program were less likely to be a SM than those that 
TABLE 2: Preprogram predictors of weight loss maintenance $(N=404)$-Model A.

\begin{tabular}{|c|c|c|c|c|}
\hline & $n$ & $\beta$ & Wald $\chi^{2}$ & OR (95\% CI) \\
\hline \multicolumn{5}{|l|}{ Marital status } \\
\hline Single/divorced/widowed & 102 & & - & \\
\hline Married & 302 & & 0.001 & \\
\hline \multicolumn{5}{|l|}{ Gender } \\
\hline Female & 327 & & - & \\
\hline Male & 77 & & 0.19 & \\
\hline \multicolumn{5}{|l|}{ Caregiver } \\
\hline No & 248 & & - & \\
\hline Yes & 156 & & 0.25 & \\
\hline \multicolumn{5}{|l|}{ Considering bariatric surgery } \\
\hline No & 312 & & - & \\
\hline Yes & 92 & & 0.24 & \\
\hline \multicolumn{5}{|l|}{ Preprogram MVPA } \\
\hline None (sedentary) & 120 & & - & 1.00 \\
\hline Any activity & 284 & 0.48 & 4.69 & $1.62(1.05-2.51)^{*}$ \\
\hline \multicolumn{5}{|l|}{ Age at the program start, years } \\
\hline $55+$ & 134 & & - & \\
\hline $45-54.9$ & 164 & & 2.84 & \\
\hline$<45$ & 106 & & 0.003 & \\
\hline \multicolumn{5}{|c|}{ Baseline body mass index, $\mathrm{kg} / \mathrm{m}^{2}$} \\
\hline Obese III $(40+)$ & 132 & & - & \\
\hline Obese II (35-39.9) & 96 & & 0.88 & \\
\hline Obese I (30-34.9) & 140 & & 0.72 & \\
\hline Overweight (25-29.9) & 36 & & 1.01 & \\
\hline \multicolumn{5}{|l|}{ Weight loss attempts } \\
\hline$\geq 20$ & 137 & & - & \\
\hline $10-19$ & 107 & & 2.32 & \\
\hline $5-9$ & 73 & & 0.02 & \\
\hline$<5$ & 87 & & 0.31 & \\
\hline
\end{tabular}

Note: MVPA: moderate-to-vigorous physical activity ${ }^{*} P<0.05 ;{ }^{* *} P<0.01 ;{ }^{* *} P<0.001$.

The Wald $\chi^{2}$ statistic, which indicates whether $\beta$ for each variable is significantly different than zero, and the variable is a significant predictor of weight loss maintenance and is reported for all variables, but an OR is only reported for significant predictors. Each variable is presented in the order in which the repeated contrasts were conducted. Thus within each variable, each level moving down the rows of the table should be compared with the level of the variable in the row immediately above it. Thus, ORs should be interpreted as the change in the likelihood of being a successful maintainer (SM) that results in a one-unit increase in the predictor variable represented by a move one row down in the table.

completed at least 12 months $(\mathrm{OR}=0.55,95 \% \mathrm{CI}=0.32-$ 0.94); respondents rating Phase I weight loss as acceptable were more likely to be SM than respondents rating weight loss as good or excellent $(\mathrm{OR}=2.19,95 \% \mathrm{CI}=1.35-3.58)$; respondents indicating it was easy to stick with diet changes $(\mathrm{OR}=2.24,95 \% \mathrm{CI}=1.25-4.00)$ and easy to continue a regular exercise routine $(\mathrm{OR}=2.15,95 \% \mathrm{CI}=1.25-3.71)$ were more likely to be SM than those rating those changes as difficult. Significant predictors of SM from Model C indicate that respondents $>6-12$ months after program were more likely be SM than respondents $>12-24$ months after program $(\mathrm{OR}=2.97,95 \% \mathrm{CI}=1.66-5.34)$; respondents insufficiently active were less likely than their sufficiently active peers to be SM (OR $=0.46,95 \% \mathrm{CI}=0.28-0.76)$; and respondents weighing themselves less than once per week were less likely to achieve SM than respondents weighing themselves at least once per week but not daily $(\mathrm{OR}=0.33,95 \% \mathrm{CI}=0.19$ 0.56). Model D produced two food management behaviors predictive of SM: limiting portion sizes $(\mathrm{OR}=2.32,95 \% \mathrm{CI}$ $=1.55-3.46)$ and limiting snacking in the evening $(\mathrm{OR}=1.71$, 95\% CI $=1.15-2.54)$.

In the final model, six factors significantly predicted SM (see Table 6 for details), including being $>12-24$ months after program compared to $>24$ months after program $(\mathrm{OR}=1.81$, $95 \%$ CI $=1.02-3.23)$; being $>6-12$ months after program compared to $>12-24$ months after program $(\mathrm{OR}=2.67$, 95\% CI $=1.48-4.84$ ); self-weighing less than once per week compared with weekly but not daily $(\mathrm{OR}=0.39,95 \% \mathrm{CI}=$ 0.23-0.66); limiting snacking in the evening ( $\mathrm{OR}=2.12,95 \%$ $\mathrm{CI}=1.33-3.38)$; limiting portion sizes $(\mathrm{OR}=1.99,95 \% \mathrm{CI}=$ 1.25-3.19); rating Phase I weight loss as acceptable compared with good/excellent $(\mathrm{OR}=2.21,95 \% \mathrm{CI}=1.28-3.80)$; and 
TABLE 3: In-program predictors of weight loss maintenance $(N=428)$-Model B.

\begin{tabular}{|c|c|c|c|c|}
\hline & $n$ & $\beta$ & Wald $\chi^{2}$ & OR (95\% CI) \\
\hline \multicolumn{5}{|l|}{ In-program weight loss } \\
\hline Not clinically significant $(<5 \%)$ & 208 & & - & \\
\hline Clinically significant ( $\geq 5 \%)$ & 220 & & 3.45 & \\
\hline \multicolumn{5}{|l|}{ Months in the program } \\
\hline$>12$ & 94 & & - & 1.00 \\
\hline$>6-12$ & 182 & -0.60 & 4.73 & $0.55(0.32-0.94)^{*}$ \\
\hline$\leq 6$ & 152 & -0.09 & 0.14 & $0.92(0.58-1.46)$ \\
\hline \multicolumn{5}{|l|}{ Perceived Phase I weight loss } \\
\hline Good/excellent & 228 & & - & 1.00 \\
\hline Acceptable & 110 & 0.79 & 9.91 & $2.19(1.35-3.58)^{* *}$ \\
\hline Poor/disappointing & 90 & -0.41 & 1.85 & $0.67(0.37-1.20)$ \\
\hline \multicolumn{5}{|l|}{ Perceived Phase I effort/success balance } \\
\hline Success $<$ effort & 179 & & - & \\
\hline Success $=$ effort & 188 & & 0.27 & \\
\hline Success $>$ effort & 61 & & 0.88 & \\
\hline \multicolumn{5}{|l|}{ Perceived difficulty to } \\
\hline \multicolumn{5}{|l|}{ Start an exercise routine } \\
\hline Difficult to extremely difficult & 244 & & - & \\
\hline Easy to extremely easy & 184 & & 1.39 & \\
\hline \multicolumn{5}{|l|}{ Change diet } \\
\hline Difficult to extremely difficult & 258 & & - & \\
\hline Easy to extremely easy & 170 & & 1.91 & \\
\hline \multicolumn{5}{|l|}{ Lose weight } \\
\hline Difficult to extremely difficult & 267 & & - & \\
\hline Easy to extremely easy & 161 & & 2.99 & \\
\hline \multicolumn{5}{|l|}{ Continue regular exercise routine } \\
\hline Difficult to extremely difficult & 313 & & - & 1.00 \\
\hline Easy to extremely easy & 115 & 0.77 & 7.56 & $2.15(1.25-3.71)^{* *}$ \\
\hline \multicolumn{5}{|l|}{ Stick with diet changes } \\
\hline Difficult to extremely difficult & 331 & & - & 1.00 \\
\hline Easy to extremely easy & 97 & 0.80 & 7.37 & $2.24(1.25-4.00)^{* *}$ \\
\hline
\end{tabular}

Note: ${ }^{*} P<0.05 ;{ }^{* *} P<0.01 ;{ }^{* * *} P<0.001$.

The Wald $\chi^{2}$ statistic, which indicates whether $\beta$ for each variable is significantly different than zero, and the variable is a significant predictor of weight loss maintenance and is reported for all variables, but an OR is only reported for significant predictors. Each variable is presented in the order in which the repeated contrasts were conducted. Thus, within each variable, each level moving down the rows of the table should be compared with the level of the variable in the row immediately above it. Thus, ORs should be interpreted as the change in the likelihood of being a successful maintainer (SM) that results in a one-unit increase in the predictor variable represented by a move one row down in the table.

perceiving it to be easy to continue a regular exercise routine as compared with difficult $(\mathrm{OR}=2.40,95 \% \mathrm{CI}=1.42-4.06)$.

\section{Discussion}

In agreement with published research [38], results from this study suggest that the likelihood of successfully maintaining weight loss diminishes over time, peaking in our survey respondents in the 6-12-month postprogram timeframe and decreasing in a stepwise fashion over time.

Preprogram physical activity level significantly predicted WLM, but only in the regression model that included preprogram predictors. However, results from the comprehensive predictor model of our study suggest no significant preprogram predictors of WLM. This is a positive finding from a population-based perspective in that it shows the program works similarly in a real-world environment with people of varying demographic characteristics, weight loss histories, $\mathrm{BMI}$, and PA.

Respondents who perceived their early program weight loss as acceptable were more than twice as likely to achieve WLM as those who rated their weight loss as good or excellent. This finding is similar to prior research that suggests that unrealistic weight loss expectations are associated with dropout from weight management programs [39-41] and that program completers achieve results that closely match preprogram expectations [42]. Interventionists should frequently assess and discuss perception of in-program weight loss, especially early, to make sure that participants perceive that they are gradually meeting modest, realistic weight loss 
TABLE 4: Postprogram predictors of weight loss maintenance $(N=404)$-Model C.

\begin{tabular}{|c|c|c|c|c|}
\hline & $n$ & $\beta$ & Wald $\chi^{2}$ & OR $(95 \% \mathrm{CI})$ \\
\hline \multicolumn{5}{|l|}{ Months postprogram } \\
\hline$>24$ & 112 & & - & \\
\hline$>12-24$ & 135 & 0.24 & 0.69 & $1.27(0.72-2.21)$ \\
\hline$>6-12$ & 92 & 1.09 & 13.33 & $2.97(1.66-5.34)^{* * *}$ \\
\hline$\leq 6$ & 65 & 0.48 & 1.68 & $1.61(0.78-3.31)$ \\
\hline \multicolumn{5}{|l|}{ Self-weighing frequency } \\
\hline At least once every day & 39 & & - & \\
\hline At least once per week but not daily & 190 & -0.28 & 0.52 & $0.76(0.35-1.62)$ \\
\hline Less than once per week & 120 & -1.11 & 16.51 & $0.33(0.19-0.56)^{* * *}$ \\
\hline Never & 55 & 0.42 & 1.27 & $1.53(0.73-3.19)$ \\
\hline \multicolumn{5}{|l|}{ Current weight loss method } \\
\hline Using both physical activity and diet & 209 & & - & \\
\hline Using physical activity or diet alone & 126 & & 1.41 & \\
\hline Not currently trying to lose weight & 69 & & 0.004 & \\
\hline \multicolumn{5}{|l|}{ Current level of physical activity } \\
\hline Meeting guidelines & 133 & & - & \\
\hline Insufficiently active & 191 & -0.77 & 9.37 & $0.46(0.28-0.76)^{* *}$ \\
\hline Sedentary & 80 & 0.06 & 0.05 & $1.07(0.59-1.93)$ \\
\hline \multicolumn{5}{|l|}{ Eating breakfast daily } \\
\hline No & 226 & & - & \\
\hline Yes & 178 & & 0.03 & \\
\hline \multicolumn{5}{|l|}{ Keeping a physical activity log } \\
\hline No & 363 & & - & \\
\hline Yes & 41 & & 0.94 & \\
\hline \multicolumn{5}{|l|}{ Currently exercising at a gym or WMP site } \\
\hline No & 293 & & - & \\
\hline Yes & 111 & & 1.22 & \\
\hline
\end{tabular}

Note: WMP: weight management program. ${ }^{*} P<0.05 ;{ }^{* *} P<0.01 ;{ }^{* * *} P<0.001$.

The Wald $\chi^{2}$ statistic, which indicates whether $\beta$ for each variable is significantly different than zero, and the variable is a significant predictor of weight loss maintenance and is reported for all variables, but an OR is only reported for significant predictors. Each variable is presented in the order in which the repeated contrasts were conducted. Thus within each variable, each level moving down the rows of the table should be compared with the level of the variable in the row immediately above it. Thus, ORs should be interpreted as the change in the likelihood of being a successful maintainer (SM) that results in a one-unit increase in the predictor variable represented by a move one row down in the table.

goals. In contrast, individuals that perceive weight loss as good or excellent may believe the behavior change process to be easy, underestimating the vigilance and cognitive restraint [43] needed to maintain such changes, leading to overconfidence, dropout, and weight regain/cycling.

The perception that maintaining a regular exercise routine was easy (compared with difficult) was predictive of WLM, suggesting another target for intervention. This confirms other research findings [4] that an individual's selfefficacy, or belief in their ability to accomplish a behavior [44] - in this case exercise-is important for sustaining weight loss. SM were more likely to meet PA guidelines. However, contrary to prior research $[4,7,45]$, postprogram PA level was not predictive of WLM in the final regression model though our measurement of PA was dissimilar to prior studies.

Postprogram behaviors were predictive of WLM and should be considered as education components that are incorporated later in WMPs, reinforced with participants upon completing WMPs, and targeted for "booster" postprogram interventions. These included weekly weighing, limiting snacking in the evening, and limiting portion sizes. In concordance with prior studies [7], self-weighing was predictive of SM, specifically self-weighing at least once per week as compared to less frequent weighing. In addition, it would be beneficial to work with participants to develop long-term strategies for limiting evening snacking (e.g., brushing teeth immediately after dinner, drinking water instead of snacking, and limiting the availability of snacks in the home) and limiting portion sizes (e.g., using portion control dishware, learning to measure portions accurately, and immediately putting half of a dinner in a to-go box when eating out). These strategies can easily be gleaned from surveys or interviews with individuals successful at WLM.

It is critical that the findings of the current study be viewed in the appropriate context. The program we evaluated is a community-based, public insurance benefit for working adults in a rural state in the USA (West Virginia) that has some of the highest rates of chronic disease in the country. Its development was informed by evidence-based programs (i.e., Diabetes Prevention Program) but adapted to 
TABLE 5: Postprogram predictors of weight loss maintenance $(N=450)$-Model D.

\begin{tabular}{|c|c|c|c|c|}
\hline & $n$ & $\beta$ & Wald $\chi^{2}$ & OR (95\% CI) \\
\hline \multicolumn{5}{|c|}{ Limiting snacking in the evening } \\
\hline No & 197 & & - & \\
\hline Yes & 253 & 0.53 & 6.90 & $1.71(1.15-2.54)^{* *}$ \\
\hline \multicolumn{5}{|c|}{ Limiting amount of fat consumed } \\
\hline No & 233 & & - & \\
\hline Yes & 217 & & 0.42 & \\
\hline \multicolumn{5}{|c|}{ Eating out less often } \\
\hline No & 242 & & - & \\
\hline Yes & 208 & & 2.11 & \\
\hline \multicolumn{5}{|c|}{ Limiting portion size at meals } \\
\hline No & 188 & & - & \\
\hline Yes & 262 & 0.84 & 16.71 & $2.32(1.55-3.46)^{* * *}$ \\
\hline \multicolumn{5}{|c|}{ Keeping a food log or journal } \\
\hline No & 348 & & - & \\
\hline Yes & 102 & & 3.21 & \\
\hline \multicolumn{5}{|c|}{ Limiting soda or sweetened drinks } \\
\hline No & 173 & & - & \\
\hline Yes & 277 & & 0.01 & \\
\hline \multicolumn{5}{|c|}{ Counting calories } \\
\hline No & 305 & & - & \\
\hline Yes & 145 & & 0.89 & \\
\hline
\end{tabular}

Note: ${ }^{*} P<0.05 ;{ }^{* *} P<0.01 ;{ }^{* *} P<0.001$.

The Wald $\chi^{2}$ statistic, which indicates whether $\beta$ for each variable is significantly different than zero, and the variable is a significant predictor of weight loss maintenance and is reported for all variables, but an OR is only reported for significant predictors. Each variable is presented in the order in which the repeated contrasts were conducted. Thus, within each variable, each level moving down the rows of the table should be compared with the level of the variable in the row immediately above it. Thus, ORs should be interpreted as the change in the likelihood of being a successful maintainer (SM) that results in a one-unit increase in the predictor variable represented by a move one row down in the table.

be contextually appropriate and sustainable. Recent reviews and meta-analyses of randomized, controlled trials (e.g., [46]) have elucidated findings from such work. Thus, contextspecific findings of our evaluation that are incongruent with others' (e.g., nonsignificant PA-WLM relationship) may be a result of the different setting, intervention approach, and/or assessment methods of our work from that of RCTs, and the limitations of our study are discussed in what follows. First, we used an inclusive definition of WLM as the outcome variable in agreement with recent recommendations [4, 11]. A more conservative definition of WLM in weight loss amount and/or length of maintenance such as those used by the NWCR and IOM [7, 47] may have yielded different results. Second, preprogram factors were assessed retrospectively. Though half of the respondents began the program within two years of this project, they may have begun up to four years prior to the survey. This time delay may have limited the ability of respondents to accurately assess some variables. To address this limitation, we categorized preprogram PA responses as none or some because it is likely that people were able to recall the difference between doing any or no PA rather than specific minutes of PA in a week. Third, the majority of predictor variables and current weight used to categorize WLM were assessed via a self-report. Such subjective reports of perceptions are relevant as intervention targets, but selfreport of weight and PA has inherent weaknesses. Further, some items in our evaluation survey were taken from the current evidence base and are specific to this evaluation but not yet validated. Additionally, generalizability of the findings is limited to participants in similar insurance-sponsored programs because a large portion of survey respondents are white, full-time employed, and married women over 45 years old. However, these demographics are similar to studies related to other formal programs and the NWCR sample [13]. Also, our response rate (39.6\%) may be considered less than ideal, but it is consistent with a meta-analysis of survey research (39.6\%) [48]. Sampling error was controlled by inviting all members of the population to complete the survey, and nonresponse error appears low because responders did not differ from nonresponders in any of the key variables such as $\mathrm{BMI}$, program completion, or $5 \%$ weight loss rate.

\section{Conclusions}

Despite the aforementioned limitations, modifiable perceptions and behaviors predictive of WLM that could be targets of future interventions were identified in this study. Many SM in the current study were able to achieve and maintain a clinically meaningful amount of weight loss, providing valuable guidance for other programs. The results suggest that weight loss interventionists should change intervention targets as participants move through a WMP, in concordance 
TABLE 6: Final model predicting weight loss maintenance $(N=428)$.

\begin{tabular}{|c|c|c|c|c|}
\hline & $n$ & $\beta$ & Wald $\chi^{2}$ & OR $(95 \% \mathrm{CI})$ \\
\hline \multicolumn{5}{|l|}{ Preprogram MVPA } \\
\hline None (sedentary) & 130 & & - & \\
\hline Any activity & 298 & & 0.05 & \\
\hline \multicolumn{5}{|l|}{ Perceived Phase I weight loss } \\
\hline Good/excellent & 227 & & - & 1.00 \\
\hline Acceptable & 112 & 0.79 & 8.17 & $2.21(1.28-3.80)^{* *}$ \\
\hline Poor/disappointing & 89 & -0.48 & 2.14 & $0.62(0.33-1.18)$ \\
\hline \multicolumn{5}{|l|}{ Months in the program } \\
\hline$>12$ & 95 & & - & \\
\hline$>6-12$ & 181 & & 1.63 & \\
\hline$\leq 6$ & 152 & & 0.05 & \\
\hline \multicolumn{5}{|c|}{ Perceived difficulty of sticking with diet changes } \\
\hline Difficult to extremely difficult & 331 & & - & \\
\hline Easy to extremely easy & 97 & & 2.67 & \\
\hline \multicolumn{5}{|c|}{ Perceived difficulty of continuing exercise routine } \\
\hline Difficult to extremely difficult & 313 & & - & 1.00 \\
\hline Easy to extremely easy & 115 & 0.88 & 10.63 & $2.40(1.42-4.06)^{* * *}$ \\
\hline \multicolumn{5}{|l|}{ Current level of physical activity } \\
\hline Meeting guidelines & 146 & & - & \\
\hline Insufficiently active & 200 & & 0.76 & \\
\hline Sedentary & 82 & & 0.18 & \\
\hline \multicolumn{5}{|l|}{ Months after program } \\
\hline$>24$ & 121 & & - & 1.00 \\
\hline$>12-24$ & 145 & 0.59 & 4.04 & $1.81(1.02-3.23)^{*}$ \\
\hline$>6-12$ & 98 & 0.98 & 10.60 & $2.67(1.78-4.84)^{* * *}$ \\
\hline$\leq 6$ & 64 & 0.18 & 0.23 & $1.20(0.57-2.54)$ \\
\hline \multicolumn{5}{|l|}{ Self-weighing frequency } \\
\hline At least once every day & 36 & & - & 1.00 \\
\hline At least once per week but not daily & 207 & -0.79 & 3.32 & $0.45(0.19-1.06)$ \\
\hline Less than once per week & 127 & -0.96 & 12.12 & $0.39(0.23-0.66)^{* * *}$ \\
\hline Never & 58 & 0.27 & 0.45 & $1.31(0.59-2.91)$ \\
\hline \multicolumn{5}{|l|}{ Limiting snacking in the evening } \\
\hline No & 188 & & - & 1.00 \\
\hline Yes & 240 & 0.75 & 9.87 & $2.12(1.33-3.38)^{* *}$ \\
\hline \multicolumn{5}{|l|}{ Limiting portion size at meals } \\
\hline No & 180 & & - & 1.00 \\
\hline Yes & 248 & 0.69 & 8.27 & $1.99(1.25-3.19)^{* *}$ \\
\hline
\end{tabular}

Note: $\mathrm{MVPA}=$ moderate-to-vigorous physical activity. ${ }^{*} P<0.05 ;{ }^{* *} P<0.01 ;{ }^{* * *} P<0.001$.

The Wald $\chi^{2}$ statistic, which indicates whether $\beta$ for each variable is significantly different than zero, and the variable is a significant predictor of weight loss maintenance and is reported for all variables, but an OR is only reported for significant predictors. Each variable is presented in the order in which the repeated contrasts were conducted. Thus within each variable, each level moving down the rows of the table should be compared with the level of the variable in the row immediately above it. Thus, ORs should be interpreted as the change in the likelihood of achieving weight loss maintenance that results in a one-unit increase in the predictor variable represented by a move one row down in the table.

with the shift from cognitive to behavioral processes of change as individuals progress through the stages of change [31]. Early in a program, interventionists may want to assess and discuss weight loss and behavior change perceptions as these may reflect participant self-efficacy and, ultimately, participant retention. As individuals progress through a program and shift toward maintenance of weight loss, interventionists are encouraged to focus attention on behaviors in developing maintenance plans, such as weekly weighing, limiting snacking in the evening, limiting portion sizes, and being physically active every day.

\section{Conflict of Interests}

The authors declare that there is no conflict of interests regarding the publication of this paper. 


\section{Acknowledgment}

This research was funded by the State of West Virginia Public Employees Insurance Agency (PEIA). PEIA assisted with the development of the survey and provided the books used as a survey completion incentive. PEIA was not involved in the data collection or analysis and did not have to approve the paper prior to submission.

\section{References}

[1] C. C. Curioni and P. M. Lourenço, "Long-term weight loss after diet and exercise: a systematic review," International Journal of Obesity, vol. 29, no. 10, pp. 1168-1174, 2005.

[2] T. Wu, X. Gao, M. Chen, and R. M. van Dam, "Long-term effectiveness of diet-plus-exercise interventions vs. diet-only interventions for weight loss: a meta-analysis: obesity management," Obesity Reviews, vol. 10, no. 3, pp. 313-323, 2009.

[3] J. C. M. Barte, N. C. W. Ter Bogt, R. P. Bogers et al., "Maintenance of weight loss after lifestyle interventions for overweight and obesity, a systematic review," Obesity Reviews, vol. 11, no. 12, pp. 899-906, 2010.

[4] K. Elfhag and S. Rössner, "Who succeeds in maintaining weight loss? A conceptual review of factors associated with weight loss maintenance and weight regain," Obesity Reviews, vol. 6, no. 1, pp. 67-85, 2005.

[5] G. Blackburn, "Effect of degree of weight loss on health benefits," Obesity Research, vol. 3, pp. 211s-216s, 1995.

[6] National Institutes of Health, Clinical Guidelines on the Identification, Evaluation, and Treatment of Overweight and Obesity in Adults: The Evidence Report, National Heart Lung and Blood Institute, 1998.

[7] R. R. Wing and J. O. Hill, "Successful weight loss maintenance," Annual Review of Nutrition, vol. 21, pp. 323-341, 2001.

[8] G. Cutter, S. S. Jeor, R. Brunner et al., "Methodological issues in weight cycling," Annals of Behavioral Medicine, vol. 18, no. 4, pp. 280-289, 1996.

[9] G. D. Foster, D. B. Sarwer, and T. A. Wadden, "Psychological effects of weight cycling in obese persons: a review and research agenda," Obesity Research, vol. 5, no. 5, pp. 474-488, 1997.

[10] A.-C. Vergnaud, S. Bertrais, J.-M. Oppert et al., "Weight fluctuations and risk for metabolic syndrome in an adult cohort," International Journal of Obesity, vol. 32, no. 2, pp. 315-321, 2007.

[11] J. Stevens, K. P. Truesdale, J. E. McClain, and J. Cai, "The definition of weight maintenance," International Journal of Obesity, vol. 30, no. 3, pp. 391-399, 2006.

[12] T. A. Wadden, V. L. Webb, C. H. Moran, and B. A. Bailer, "Lifestyle modification for obesity: new developments in diet, physical activity, and behavior therapy," Circulation, vol. 125, no. 9, pp. 1157-1170, 2012.

[13] M. L. Klem, R. R. Wing, M. T. McGuire, H. M. Seagle, and J. O. Hill, "A descriptive study of individuals successful at long-term maintenance of substantial weight loss," The American Journal of Clinical Nutrition, vol. 66, no. 2, pp. 239-246, 1997.

[14] R. W. Jeffery, W. M. Bjornson-Benson, B. S. Rosenthal, C. L. Kurth, and M. M. Dunn, "Effectiveness of monetary contracts with two repayment schedules on weight reduction in men and women from self-referred and population samples," Behavior Therapy, vol. 15, no. 3, pp. 273-279, 1984.

[15] M. Katahn, J. Pleas, M. Thackrey, and K. A. Wallston, "Relationship of eating and activity self-reports to follow-up weight maintenance in the massively obese," Behavior Therapy, vol. 13, no. 4, pp. 521-528, 1982.

[16] S. Kayman, W. Bruvold, and J. S. Stern, "Maintenance and relapse after weight loss in women: behavioral aspects," The American Journal of Clinical Nutrition, vol. 52, no. 5, pp. 800807,1990 .

[17] A. J. Stunkard and S. Messick, "The three-factor eating questionnaire to measure dietary restraint, disinhibition and hunger," Journal of Psychosomatic Research, vol. 29, no. 1, pp. 71-83, 1985.

[18] R. C. Baker and D. S. Kirschenbaum, "Self-monitoring may be necessary for successful weight control," Behavior Therapy, vol. 24, no. 3, pp. 377-394, 1993.

[19] M. T. McGuire, R. R. Wing, M. L. Klem et al., "What predicts weight regain in a group of successful weight losers?" Journal of Consulting and Clinical Psychology, vol. 67, pp. 177-185, 1999.

[20] G. C. Williams, V. M. Grow, Z. R. Freedman, R. M. Ryan, and E. L. Deci, "Motivational predictors of weight loss and weight-loss maintenance," Journal of Personality and Social Psychology, vol. 70, no. 1, pp. 115-126, 1996.

[21] World Economic Forum Workplace Wellness Alliance, Making the Right Investment: Employee Health and the Power of Metrics, World Economic Forum Workplace Wellness Alliance, Geneva, Switzerland, 2013.

[22] National Institute for Health Care Management Foundation, Health Plans Emerging as Pragmatic Partners in Fight against Obesity, National Institute for Health Care Management Foundation, Washington, DC, USA, 2005.

[23] C. G. Abildso, S. J. Zizzi, and B. Reger-Nash, "Evaluating an insurance-sponsored weight management program with the RE-AIM Model, West Virginia, 2004-2008," Preventing Chronic Disease, vol. 7, no. 3, p. A46, 2010.

[24] C. G. Abildso, S. J. Zizzi, and S. J. Fitzpatrick, "Predictors of clinically significant weight loss and participant retention in an insurance-sponsored community-based weight management program," Health Promotion Practice, vol. 14, pp. 580-588, 2013.

[25] D. A. Dillman, Mail and Internet Surveys: The Tailored Design Method, John Wiley \& Sons, Hoboken, NJ, USA, 2nd edition, 2007.

[26] R. C. Brownson, D. A. Jones, M. Pratt, C. Blanton, and G. W. Heath, "Measuring physical activity with the behavioral risk factor surveillance system," Medicine and Science in Sports and Exercise, vol. 32, no. 11, pp. 1913-1918, 2000.

[27] C. Abildso, S. Zizzi, D. Gilleland, J. Thomas, and D. Bonner, "A mixed methods evaluation of a 12-week insurance-sponsored weight management program incorporating cognitivebehavioral counseling," Journal of Mixed Methods Research, vol. 4, no. 4, pp. 278-294, 2010.

[28] R. R. Wing, R. Koeske, L. H. Epstein, M. P. Nowalk, W. Gooding, and D. Becker, "Long-term effects of modest weight loss in type II diabetic patients," Archives of Internal Medicine, vol. 147, no. 10, pp. 1749-1753, 1987.

[29] I. L. Mertens and L. F. van Gaal, "Overweight, obesity, and blood pressure: the effects of modest weight reduction," Obesity Research, vol. 8, no. 3, pp. 270-278, 2000.

[30] L. F. van Gaal, M. A. Wauters, and I. H. de Leeuw, "The beneficial effects of modest weight loss on cardiovascular risk factors," International Journal of Obesity, vol. 21, no. 1, pp. S5-S9, 1997.

[31] J. O. Prochaska and W. F. Velicer, "The transtheoretical model of health behavior change," American Journal of Health Promotion, vol. 12, no. 1, pp. 38-48, 1997. 
[32] R. R. Wing, Behavioral Weight Control, The Guilford Press, New York, NY, USA, 2002.

[33] M. J. Franz, J. J. VanWormer, A. L. Crain et al., "Weight-loss outcomes: a systematic review and meta-analysis of weight-loss clinical trials with a minimum 1-year follow-up," Journal of the American Dietetic Association, vol. 107, no. 10, pp. 1755-1767, 2007.

[34] T. A. Wadden, M. L. Butryn, and K. J. Byrne, "Efficacy of lifestyle modification for long-term weight control," Obesity Research, vol. 12, pp. 151S-162S, 2004.

[35] A. P. Field, Discovering Statistics Using SPSS, Sage, London, UK, 3rd edition, 2009.

[36] B. G. Tabachnick and L. S. Fidell, Using Multivariate Statistics, Allyn \& Bacon, Boston, Mass, USA, 4th edition, 2000.

[37] National Heart Lung Blood Institute, "Obesity education initiative expert panel: clinical guidelines on the identification, evaluation, and treatment of overweight and obesity in adultsthe evidence report," Obesity Research, vol. 6, supplement 2, pp. 51S-179S, 1998.

[38] R. W. Jeffery, L. H. Epstein, G. T. Wilson et al., "Long-term maintenance of weight loss: current status," Health Psychology, vol. 19, no. 1, pp. 5-16, 2000.

[39] J. Polivy and C. Peter Herman, "If at first you don't succeed: false hopes of self-change," American Psychologist, vol. 57, no. 9, pp. 677-689, 2002.

[40] S. R. Sears and A. L. Stanton, "Expectancy-value constructs and expectancy violation as predictors of exercise adherence in previously sedentary women," Health Psychology, vol. 20, no. 5, pp. 326-333, 2001.

[41] F. Jones, P. Harris, and H. Waller, "Expectations of an exercise prescription scheme: an exploratory study using repertory grids," British Journal of Health Psychology, vol. 3, no. 3, pp. 277289, 1998.

[42] F. Jones, P. Harris, H. Waller, and A. Coggins, "Adherence to an exercise prescription scheme: the role of expectations, selfefficacy, stage of change and psychological well-being," British Journal of Health Psychology, vol. 10, no. 3, pp. 359-378, 2005.

[43] R. R. Wing and S. Phelan, "Long-term weight loss maintenance," The American Journal of Clinical Nutrition, vol. 82, no. 1, pp. 222S-225S, 2005.

[44] A. Bandura, "Self-efficacy: toward a unifying theory of behavioral change," Psychological Review, vol. 84, no. 2, pp. 191-215, 1977.

[45] J. W. Anderson, E. C. Konz, R. C. Frederich, and C. L. Wood, "Long-term weight-loss maintenance: a meta-analysis of US studies," The American Journal of Clinical Nutrition, vol. 74, no. 5, pp. 579-584, 2001.

[46] K. Casazza, K. R. Fontaine, A. Astrup et al., "Myths, presumptions, and facts about obesity," The New England Journal of Medicine, vol. 368, pp. 446-454, 2013.

[47] Institute of Medicine (IOM), Weighing the Options: Criteria for Evaluating Weight-Management Programs, National Academies Press, Washington, DC, USA, 1995.

[48] C. Cook, F. Heath, and R. L. Thompson, "A meta-analysis of response rates in Web- or internet-based surveys," Educational and Psychological Measurement, vol. 60, no. 6, pp. 821-836, 2000. 


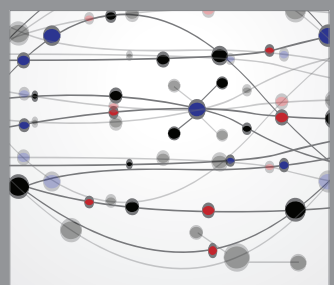

The Scientific World Journal
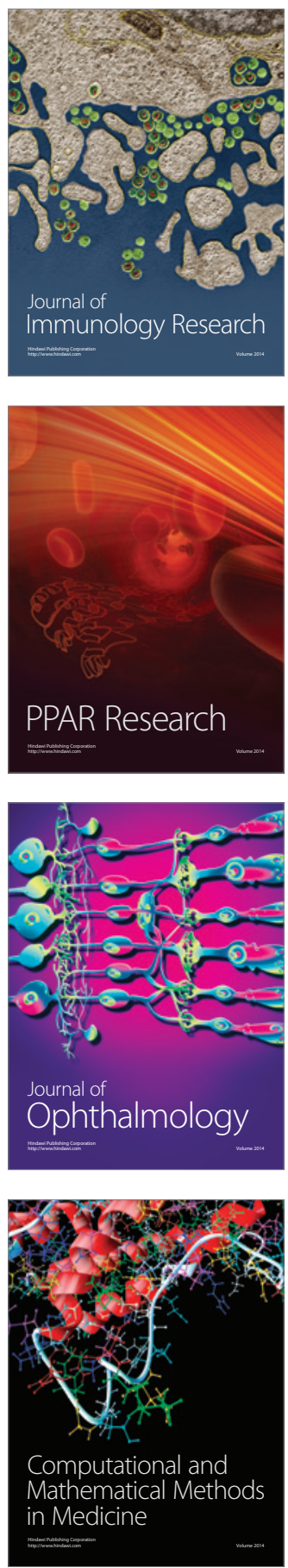

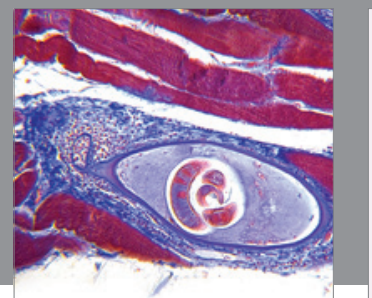

Gastroenterology

Research and Practice
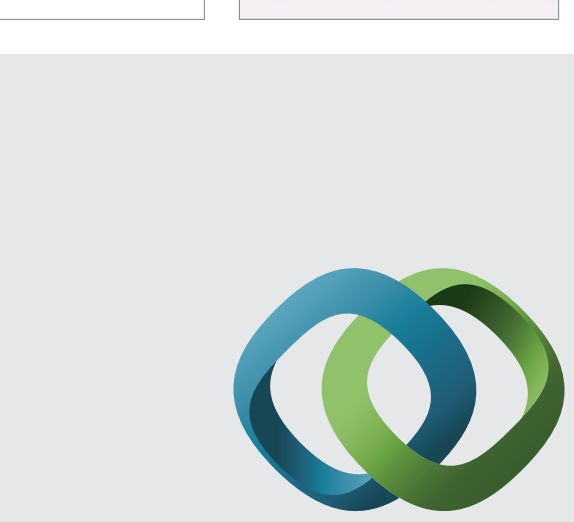

\section{Hindawi}

Submit your manuscripts at

http://www.hindawi.com
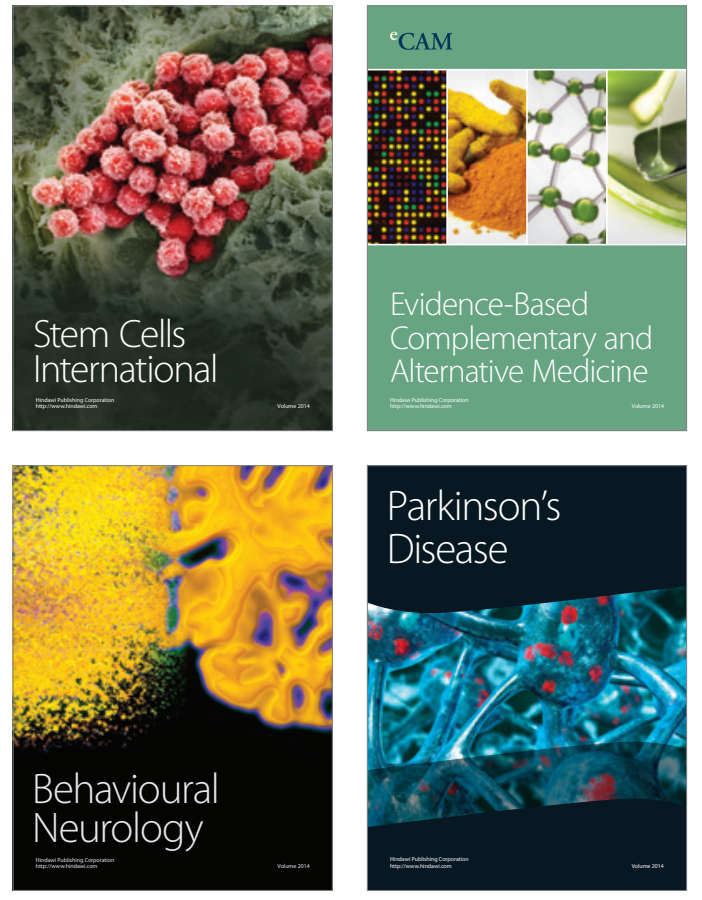
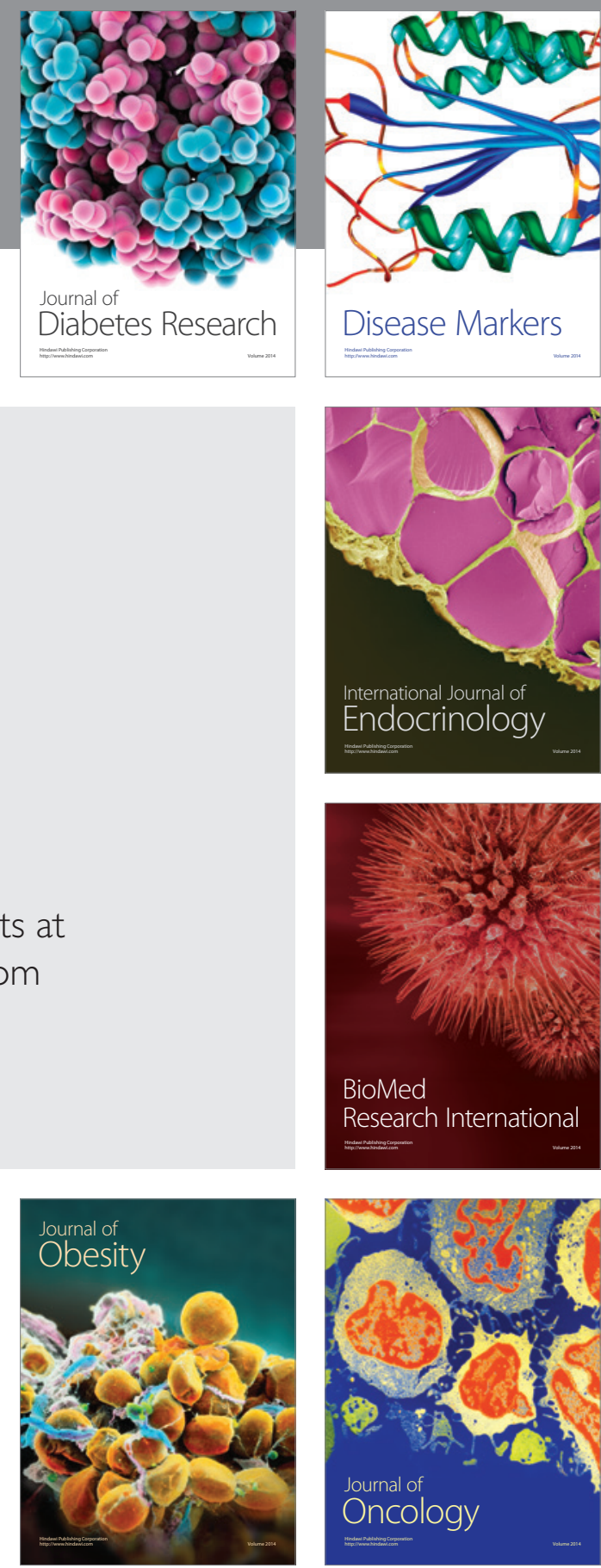

Disease Markers
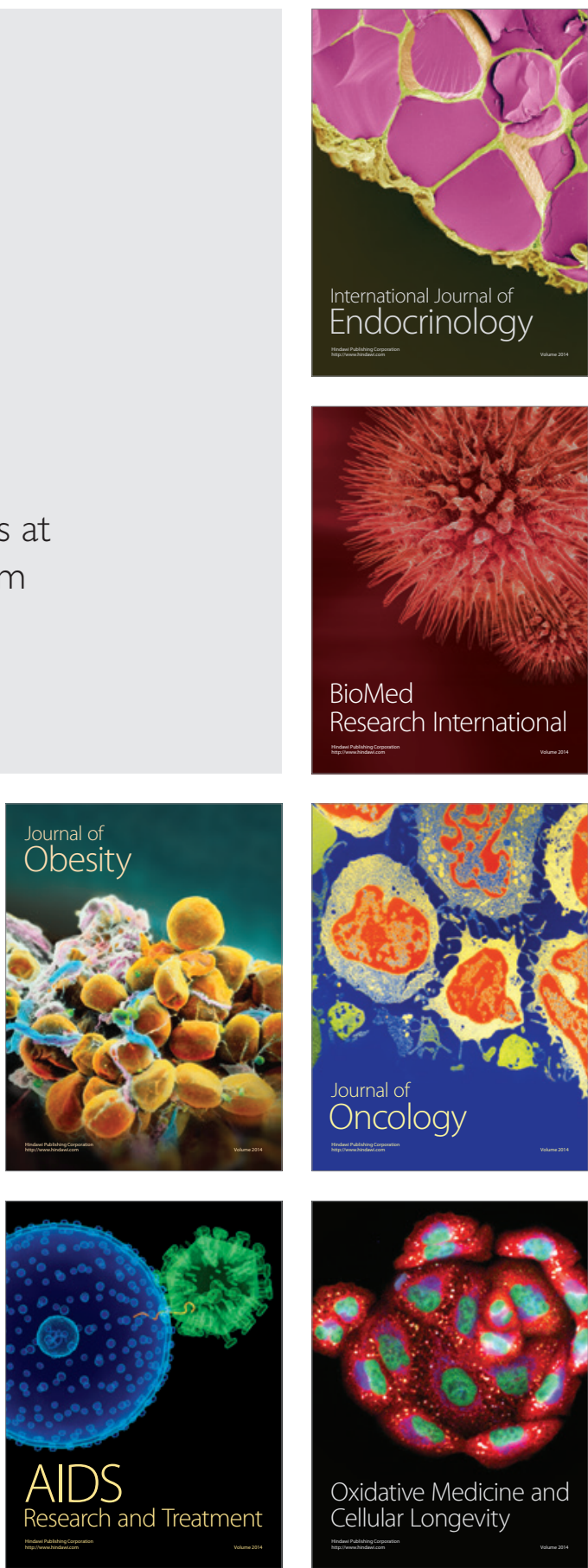